\title{
Hubungan Tingkat Pengetahuan Terhadap Outcome Klinik Pasien Diabetes Melitus Tipe 2
}

\author{
Relationship of Knowledge Level to Clinical Outcome in Type 2 Diabetes Melitus Patient
}

Laksmy Anggun Larasati ${ }^{*}$, Tri Murti Andayani, Susi Ari Kristina

Fakultas Farmasi, Universitas Gadjah Mada, Yogyakarta

Submitted: 08-02-2019 Revised: 19-03-2019 Accepted: 24-04-2019

Korespondensi : Laksmy Anggun Larasati : Email : laksmyanggun@gmail.com

\begin{abstract}
ABSTRAK
Diabetes merupakan penyakit kronis yang membutuhkan manajemen terapi dan perawatan diri agar mencapai target glikemik yang optimal. Salah satu barier kontrol glikemik yang baik adalah kurangnya pengetahuan mengenai target glikemik optimal. Tujuan penelitian ini adalah untuk mengetahui hubungan antara tingkat pengetahuan terhadap outcome klinik diabetes melitus tipe 2 di Puskesmas Kota Yogyakarta dan Kota Bantul. Penelitian ini merupakan penelitian observasional dengan rancangan cross sectional. Teknik pengambilan sampel dilakukan secara accidental sampling pada pasien yang berkunjung ke puskemas periode Oktober hingga Desember 2018 yang melibatkan 200 pasien diabetes melitus tipe 2 yang termasuk dalam kriteria inklusi. Tingkat pengetahuan pasien diukur dengan Diabetes Knowledge Questionnaire (DKQ)-24 yang memiliki 24 pertanyaan pengetahuan dan outcome klinik diperoleh dari data pengukuran laboratorium maupun dari data rekam medik saat pasien kontrol. Data karakteristik pasien dianalisis secara deskriptif. Data tingkat pengetahuan dan outcome klinik dianalisis dengan uji chi square. Hasil penelitian menunjukan bahwa skor tingkat pengetahuan memiliki nilai rata-rata 12 . Jawaban salah terbanyak terdapat pada etiologi dan self care diabetes yaitu makan terlalu banyak gula dan makanan manis adalah penyebab diabetes (97\%), olahraga teratur akan meningkatkan kebutuhan hormon insulin atau obat diabetes (82\%), reaksi insulin disebabkan oleh makanan yang terlalu banyak (84\%) dan penderita diabetes sebaiknya membersihkan luka dengan betadin dan alkohol (88\%). Pasien yang mencapai target terapi atau kadar gula darah terkontrol sebesar 106 (53\%) pasien. Uji chi square menunjukan tidak terdapat hubungan antara tingkat pengetahuan terhadap outcome klinik $(p=0,328)$. Hasil penelitian ini dapat menjadi masukan dan evaluasi konten edukasi pada pasien diabetes.

Kata kunci: Diabetes, DKQ24, tingkat pengetahuan, outcome klinik.
\end{abstract}

\section{ABSTRACT}

Diabetes is a chronic disease that requires good therapeutic management and self care to achieve optimal glycemic target. The important barrier to achieve good glycemic control is a lack of knowledge about optimal glycemic targets. The purpose of this study was to determine the relationship of the level of knowledge to clinical outcome of type 2 diabetes mellitus in Yogyakarta and Bantul primary health care. This was an observational study with a cross sectional design. The sampling technique was done by accidental sampling for patients visiting the primary health care from October to December 2018 that involved 200 type 2 diabetes mellitus patients who were included in the inclusion criteria. The level of knowledge was measured by the Diabetes Knowledge Questionnaire (DKQ)-24 which had 24 questions and the clinical outcome was obtained from laboratory measurement data as well as from medical record data when the patient was in routine control. Sociodemographic data were analyzed descriptively. The relationship between the level of knowledge and clinical outcomes was analyzed using chi square. The results showed that the knowledge level score had an average value of 12 . The most incorrect answer was in etiology and diabetes self care, which is eating too much sugar and sweet foods is the cause of diabetes (97\%), exercise regularly increasing the need of hormone insulin or diabetes medication (82\%), the insulin reaction is caused by too much food (84\%) and diabetics should clean the wound with betadine and alcohol (88\%). There were $106(53 \%)$ patients who achieved good glycemic control. Chi square test showed no relationship between the level of knowledge of clinical outcomes $(p=0.328)$. The result of this study may become a material and education content evaluation in diabetic patients.

Keywords: Diabetes, DKQ24, knowledge level, clinical outcome. 


\section{PENDAHULUAN}

Indonesia masuk dalam 10 besar negara dengan penderita diabetes terbanyak hingga mencapai 10 juta orang. Berdasarkan data dari Dinas Kesehatan Yogyakarta tahun 2012 di Provinsi Daerah Istimewa Yogyakarta (DIY) penyakit Diabetes Melitus (DM) tipe 2 menduduki urutan kelima untuk penyakit tidak menular. Salah satu barrier dalam kontrol gula darah yang baik adalah kurangnya pengetahuan atau edukasi mengenai tujuan terapi dalam kontrol gula darah optimal ${ }^{1}$. Terdapat beberapa penelitian yang menunjukan adanya hubungan signifikan antara tingkat pengetahuan pasien terhadap outcome klinik. Hasil penelitian serupa juga ditemukan pada penelitian Fenwick dkk (2013) yang mengatakan bahwa tingginya nilai $\mathrm{HbA1c}$ berkorelasi dengan rendahnya tingkat pengetahuan pasien diabetes melitus, faktor yang dapat meningkatkan pengetahuan diabetes dan outcome klinik adalah adanya edukasi diabetes yang lebih spesifik dan akses yang mudah untuk periksa atau kontrol ke fasilitas pelayanan kesehatan ${ }^{1}$. Penelitian yang dilakukan oleh Ozcelik dkk (2010) mengatakan bahwa nilai $\mathrm{HbA} 1 \mathrm{c}$ dan gula darah puasa lebih rendah pada subyek penelitian yang memiliki skor pengetahuan yang tinggi dan skor pengetahuan ditemukan pada subyek yang menerima edukasi diabetes dibandingkan yang tidak menerima edukasi diabetes $^{2}$. Sedangkan penelitian yang dilakukan oleh Alarcon dkk (2015) menunjukan hasil yang berbeda dengan penelitian yang telah disebutkan yang menyatakan bahwa tidak ada hubungan antara tingkat pengetahuan pasien terhadap kontrol glikemik pasien diabetes melitus tipe 2, namun terdapat hubungan antara tingkat pendidikan terhadap tingkat pengetahuan pasien $^{3}$. Dari pemaparan hasil penelitian tersebut peneliti ingin mengetahui hubungan antara tingkat pengetahuan terhadap outcome klinik di fasilitas pelayanan kesehatan tingkat pertama atau Puskesmas di Kota Yogyakarta dan Kota Bantul periode Oktober hingga Desember 2018.

\section{METODE}

Penelitian ini merupakan penelitian observasional dengan rancangan cross sectional dimana pengambilan sampel dilakukan secara accidental sampling di Puskesmas Kota Yogyakarta dan Puskesmas Kota Bantul periode Oktober hingga Desember 2018. Kriteria inklusi pada penelitian ini adalah pasien diabetes melitus tipe 2 dengan umur $\geq$ 18 tahun, telah menjalani kontrol rutin minimal selama 1 bulan sebelum penelitian dilakukan, terdapat data outcome klinik yang lengkap yaitu gula darah sewaktu, gula darah posprandial dan atau gula darah puasa, pasien mampu berkomunikasi dengan baik dan bersedia menjadi responden. Berdasarkan perhitungan sampel dengan tingkat kepercayaan 95\% dengan tingkat kesalahan yang dapat diterima adalah 0.05, didapatkan jumlah sampel minimal yang diperlukan adalah 82 sampel, namun peneliti memperoleh total 200 sampel. Kriteria eksklusi meliputi pasien dengan data outcome klinik tidak lengkap dan tidak dapat berkomunikasi dengan baik.

\section{Alat ukur}

Tingkat pengetahuan

Tingkat pengetahuan diukur dengan Diabetes Knowledge Questionnaire 24 (DKQ24) berisi 24 pertanyaan yang dikembangkan oleh Star County yang merupakan kuesioner hasil pengembangan dari DKQ60 dengan nilai Cronbach alpha 0.78. Aspek yang dinilai adalah informasi dasar (10 item), kontrol glikemik (7 item) dan pencegahan komplikasi (7 item). Pilihan jawaban adalah "ya", "tidak" dan "tidak tahu". Penilaian dilakukan berdasarkan jumlah item yang benar dijawab oleh subyek, jawaban benar diberi nilai 1 sedangkan jawaban yang salah atau tidak tahu diberi nilai 0 . Tingkat pengetahuan dikatakan tinggi jika skor 17-24, sedang 10-16, dan rendah 0-94. Pada penelitian ini pengelompokan tingkat 
pengetahuan berdasarkan nilai rata-rata yaitu 11.97 dapat dibulatkan menjadi 12. Kategori tingkat pengetahuan terbagi menjadi dua yaitu $<12$ dan $\geq 12$.

\section{Pengambilan data}

Pengambilan data tingkat pengetahuan dan kualitas hidup dilakukan dengan wawancara langsung kepada subyek penelitian. Pengambilan data outcome klinik berupa gula darah sewaktu, puasa, dan atau posprandial dilihat dari hasil laboratorium pasien saat kontrol rutin di puskesmas atau dilihat dari data rekam medik pasien.

\section{Analisis data}

Analisis data penelitian ini menggunakan Statistical Package for the Social Science (SPSS) software version 23. Data sosiodemografi pasien dianalisis secara deskriptif. Uji hubungan antara karakteristik pasien dengan outcome klinik dan tingkat pengetahuan dengan outcome klinik menggunakan uji chi square. Uji statistik dinyatakan signifikan jika nilai p value $<0.05$.

\section{HASIL DAN PEMBAHASAN}

Total sampel yang didapatkan adalah 200 yang terdiri dari 29\% laki-laki dan 71\% perempuan dengan rata-rata umur 58,96 tahun, dengan status marital sudah menikah $87,9 \%$, tingkat pendidikan tertinggi berada pada sekolah menengah sebanyak 53,5\%. Subyek yang rutin melakukan aktvitas fisik minimal tiga kali dalam seminggu sebanyak $42 \%$, melakukan pengaturan pola makan sebanyak $63 \%$, subyek non obesitas $92,5 \%$, durasi atau lamanya menderita diabetes $<10$ tahun sebanyak $84,5 \%$ dan komplikasi terbanyak yang diderita adalah komplikasi mikrovaskular sebanyak 13,5\% (Tabel I).

Kuesioner DKQ24 memiliki 24 item pertanyaan dengan aspek yang dinilai adalah informasi dasar (10 item), kontrol glikemik (7 item), dan pencegahan komplikasi (7 item) ${ }^{3}$. Respon dari setiap pertanyaan berupa "ya", "tidak" dan "tidak tahu" dengan skor jawaban benar adalah 1 dan salah atau tidak tahu 0 . Gambaran pengetahuan dapat dilihat pada (Tabel II).
Jawaban salah sebanyak $>50 \%$ terdapat pada etiologi diabetes melitus yaitu penyebab diabetes karena makan terlalu banyak gula dan makanan manis (97\%), penyebab umum diabetes karena kurang hormon insulin dalam tubuh (52,5\%), penyebab diabetes karena ginjal tidak bisa menyaring gula dari air seni (75\%), dan ginjal memproduksi hormon insulin (80\%). Pengetahuan tentang selfcare dengan $>50 \%$ jawaban salah terdapat pada item olahraga teratur akan meningkatkan kebutuhan hormon insulin (82\%), reaksi insulin disebabkan oleh makanan terlalu banyak (84\%), pengobatan lebih penting daripada olahraga dan menjaga pola makan untuk kontrol diabetes (59\%), penderita diabetes mengobati lukanya dengan iodine dan alkohol (88\%), stoking atau kaus kaki yang ketat tidak buruk bagi penderita diabetes $(75,5 \%)$, pola makan penderita diabetes terdiri dari makanan khusus $(85,5)$, gemetar dan berkeringat adalah tanda-tanda kadar gula darah tinggi $(73,5 \%)$, dan sering buang air kecil dan merasa haus adalah tanda-tanda kadar gula darah rendah $(75,5 \%)$. Jawaban pertanyaan dari skor DKQ24 terendah adalah yang berhubungan dengan etiologi diabetes melitus, karena pasien mempercayai bahwa diabetes disebabkan karena konsumsi gula yang tinggi dan makanan manis ${ }^{3}$. Data mengenai tingginya persentase jawaban salah pada kuesioner DKQ24 dapat bermanfaat sebagai masukan dan evaluasi konten atau isi bahan edukasi pada saat pasien kontrol rutin maupun pada program pengelolaan penyakit kronis (PROLANIS) yang dilakukan praktisi maupun tenaga kesehatan di puskesmas.

Skor rata-rata jawaban DKQ24 pada penelitian ini adalah 11.97 (dibulatkan menjadi 12) dan nilai SD 3.5, cutting point skor DKQ24 pada penelitian ini adalah 12 dan kategori pengelompokan menjadi dua yaitu $<12$ dan $\geq 12$. Pada penelitian ini pasien dengan skor pengetahuan <12 sebesar 114 (57\%) dan $\geq 12$ sebesar 86 (43\%). Jumlah pasien dengan skor pengetahuan $<12$ lebih besar dibanding jumlah pasien dengan skor $\geq 12$. Pengetahuan pasien masih rendah, hal ini sejalan dengan penelitian sebelumnya yang menyatakan 
Tabel I. Karakteristik Pasien Diabetes Melitus Tipe 2

\begin{tabular}{|c|c|c|}
\hline Karakteristik & Jumlah $(n=200)$ & Persen $(\%)$ \\
\hline \multicolumn{3}{|l|}{ Jenis Kelamin } \\
\hline Laki-laki & 58 & 29 \\
\hline Perempuan & 142 & 71 \\
\hline \multicolumn{3}{|c|}{ Umur (mean: 58,96; SD:9,0) } \\
\hline 60 tahun keatas & 117 & 58,5 \\
\hline$<60$ tahun & 83 & 41,5 \\
\hline \multicolumn{3}{|l|}{ Status } \\
\hline Menikah & 175 & 87,9 \\
\hline Janda atau Duda & 24 & 12,1 \\
\hline \multicolumn{3}{|l|}{ Tingkat Pendidikan } \\
\hline Tinggi & 19 & 9,5 \\
\hline Menengah & 107 & 53,5 \\
\hline Dasar & 46 & 23 \\
\hline Tidak Sekolah & 28 & 14 \\
\hline \multicolumn{3}{|l|}{ Status Pekerjaan } \\
\hline Bekerja & 59 & 29,5 \\
\hline Tidak Bekerja & 141 & 70,5 \\
\hline \multicolumn{3}{|c|}{ Pendapatan Keluarga } \\
\hline$>3$ Juta & 29 & 14,5 \\
\hline 1-3 Juta & 52 & 26 \\
\hline$<1$ Juta & 119 & 59,5 \\
\hline \multicolumn{3}{|l|}{ Aktivitas Fisik } \\
\hline Rutin & 84 & 42 \\
\hline Kadang-kadang & 75 & 37,5 \\
\hline Tidak Pernah & 41 & 20,5 \\
\hline \multicolumn{3}{|c|}{ Pengaturan pola makan } \\
\hline Ada & 126 & 63 \\
\hline Tidak & 74 & 37 \\
\hline \multicolumn{3}{|l|}{ Indeks Masa Tubuh } \\
\hline Obesitas & 15 & 7,5 \\
\hline Non obesitas & 185 & 92,5 \\
\hline \multicolumn{3}{|l|}{ Durasi DM } \\
\hline$\geq 10$ Tahun & 31 & 15,5 \\
\hline$<10$ tahun & 169 & 84,5 \\
\hline \multicolumn{3}{|l|}{ Komplikasi } \\
\hline Makrovaskular & 4 & 2 \\
\hline Mikrovaskular & 27 & 13,5 \\
\hline Tida ada & 169 & 84,5 \\
\hline
\end{tabular}

bahwa pengetahuan tentang diabetes pada negara berkembang masih rendah ${ }^{5,6}$.

Karakteristik pasien diuji dengan chi Square menunjukan bahwa tidak terdapat hubungan antara karakteristik pasien dengan outcome klinik yaitu jenis $\operatorname{kelamin}(\mathrm{p}=0.694)$, umur $(p=0.771)$, status marital $(p=0.239)$, tingkat pendidikan $(\mathrm{p}=0.231)$, status pekerjaan $(\mathrm{p}=0.396)$, pendapatan keluarga $(\mathrm{p}=0.665)$, durasi diabetes (0.083) adanya komplikasi $(\mathrm{p}=$ $0.382)$, pengaturan pola makan $(p=0.702)$, dan ada tidaknya aktivitas fisik $(\mathrm{p}=0.742)$. 
Tabel II. Gambaran Pengetahuan Pasien Diabetes Melitus Tipe 2 di Puskesmas

\begin{tabular}{|c|c|c|}
\hline \multirow{2}{*}{ Item pertanyaan } & \multicolumn{2}{|c|}{ Jawaban $(n=200)$} \\
\hline & Benar (\%) & Salah (\%) \\
\hline $\begin{array}{l}\text { Makan terlalu banyak gula dan makanan manis lainnya } \\
\text { adalah penyebab diabetes }\end{array}$ & $6(3)$ & $194(97)$ \\
\hline $\begin{array}{l}\text { Penyebab umum diabetes adalah kekurangan kadar hormone } \\
\text { insulin yang efektif di dalam tubuh }\end{array}$ & $95(47,5)$ & $105(52,5)$ \\
\hline $\begin{array}{l}\text { Diabetes disebabkan oleh kegagalan ginjal dalam menyaring } \\
\text { gula dari air seni }\end{array}$ & $50(25)$ & $150(75)$ \\
\hline Ginjal memproduksi hormon insulin & $40(20)$ & $160(80)$ \\
\hline $\begin{array}{l}\text { Pada kasus diabetes yang tidak ditangani, kadar gula dalam } \\
\text { tubuh biasanya meningkat }\end{array}$ & $184(92)$ & $16(8)$ \\
\hline Jika saya penderita diabetes, anak-anak saya mempunyai & & \\
\hline $\begin{array}{l}\text { kesempatan yang lebih besar untuk menjadi penderita } \\
\text { diabetes }\end{array}$ & $125(62,5)$ & $75(37,5)$ \\
\hline Diabetes dapat disembuhkan & $109(54,5)$ & $91(45,5)$ \\
\hline Kadar gula darah puasa 210 terlalu tinggi & $165(82,5)$ & $35(17,5)$ \\
\hline $\begin{array}{l}\text { Cara terbaik untuk memeriksa diabetes saya adalah dengan } \\
\text { melakukan tes urin }\end{array}$ & $133(66,5)$ & $67(33,5)$ \\
\hline $\begin{array}{l}\text { Olahraga teratur akan meningkatkan kebutuhan akan hormon } \\
\text { insulin atau obat diabetes lainnya }\end{array}$ & $36(18)$ & $164(82)$ \\
\hline $\begin{array}{l}\text { Terdapat dua tipe diabetes: tipe } 1 \text { (ketergantungan terhadap } \\
\text { insulin) dan tipe } 2 \text { (resistensi terhadap insulin) }\end{array}$ & $106(53)$ & $94(47)$ \\
\hline Reaksi insulin disebabkan oleh makanan yang terlalu banyak & $32(16)$ & $168(84)$ \\
\hline $\begin{array}{l}\text { Pengobatan lebih penting dari pada menjaga pola makan dan } \\
\text { olahraga untuk mengontrol diabetes saya }\end{array}$ & $82(41)$ & $118(59)$ \\
\hline Diabetes sering menyebabkan peredaran (darah) yang buruk & $148(74)$ & $52(26)$ \\
\hline $\begin{array}{l}\text { Luka dan luka gores pada penderita diabetes sembuh lebih } \\
\text { lama }\end{array}$ & $169(84,5)$ & $31(15,5)$ \\
\hline $\begin{array}{l}\text { Penderita diabetes sebaiknya lebih berhati-hati ketika } \\
\text { memotong kuku mereka }\end{array}$ & $169(84,5)$ & $31(15,5)$ \\
\hline $\begin{array}{l}\text { Seorang penderita diabetes sebaiknya membersihkan lukanya } \\
\text { dengan iodine dan alkohol }\end{array}$ & $24(12)$ & $176(88)$ \\
\hline $\begin{array}{l}\text { Cara saya menyiapkan makanan saya sama pentingnya } \\
\text { dengan makanan yang saya makan }\end{array}$ & $164(82)$ & $36(18)$ \\
\hline Diabetes dapat merusak ginjal saya & $168(84)$ & $32(16)$ \\
\hline $\begin{array}{l}\text { Diabetes dapat menyebabkan mati rasa di tangan, jari, dan } \\
\text { kaki saya }\end{array}$ & $160(80)$ & $40(20)$ \\
\hline $\begin{array}{l}\text { Gemetaran dan berkeringat adalah tanda-tanda memiliki } \\
\text { kadar gula darah yang tinggi }\end{array}$ & $53(26,5)$ & $147(73,5)$ \\
\hline $\begin{array}{l}\text { Sering buang air kecil dan merasa haus adalah tanda-tanda } \\
\text { memiliki kadar gula darah rendah }\end{array}$ & $94(47)$ & $106(53)$ \\
\hline $\begin{array}{l}\text { Stoking atau kauskaki elastis yang ketat tidak buruk bagi } \\
\text { penderita diabetes }\end{array}$ & $49(24,5)$ & $151(75,5)$ \\
\hline $\begin{array}{l}\text { Pola makan penderita diabetes sebagian besar terdiri dari } \\
\text { makanan khusus }\end{array}$ & $29(14,5)$ & $171(85,5)$ \\
\hline
\end{tabular}


Tabel III. Hubungan Antara Tingkat Pengetahuan Terhadap Outcome Klinik

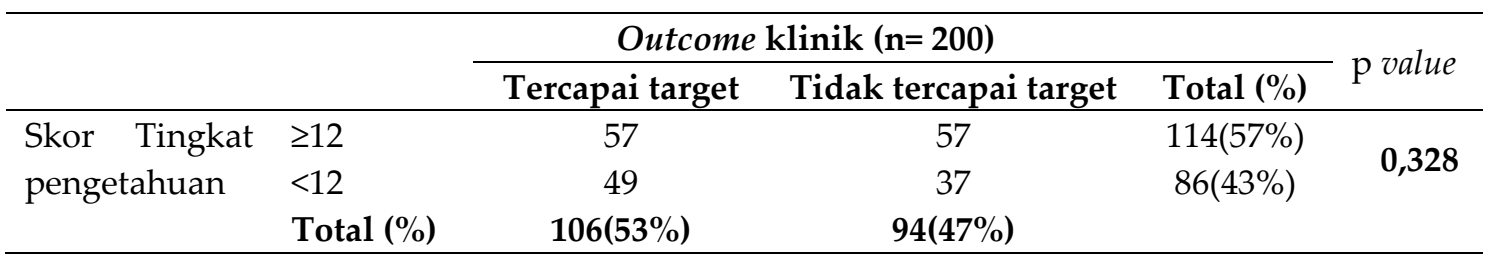

Penentuan kategori outcome klinik berdasarkan standar dari American Diabetes Association (ADA) tahun 2018 menjadi tercapai dan tidak tercapai target terapi. Nilai A1C $<7.0 \%$ (53 $\mathrm{mmol} / \mathrm{mol}$ ), gula darah sewaktu atau preprandial $80-130 \mathrm{mg} / \mathrm{dl}(4.4-7.2$ $\mathrm{mmol} / \mathrm{L})$, gula darah puasa 100-125 mmol (5.6$6.9 \mathrm{mmol} / \mathrm{L}$ ) dan nilai gula darah posprandial $<180 \mathrm{mg} / \mathrm{dl}(10.0 \mathrm{mmol} / \mathrm{L})^{7}$.

Uji chi square menunjukan tidak ada hubungan antara tingkat pengetahuan terhadap outcome klinik ( $\mathrm{p}=0.328$ ) (Tabel III). Pada penelitian ini tidak ditemukan hubungan antara tingkat pengetahuan terhadap outcome klinik hal ini dapat terjadi kemungkinan karena tidak semua pasien yang mengikuti penelitan termasuk dalam PROLANIS, sehingga kemungkinan banyak pasien yang tidak mendapatkan pengetahuan atau edukasi mengenai diabetes, terapi, perawatan diri atau self care, dan pencegahan komplikasi karena pengetahuan dapat mempengaruhi outcome klinik pasien ${ }^{8}$. Pasien yang belum lama terdiagnosa diabetes kemungkinan kurang mendapatkan pengetahuan diabetes dibandingkan dengan pasien yang telah lama terdiagnosa diabetes sehingga dapat mempengaruhi self care atau perawatan diri pasien yang berakibat pada ketidaktercapaian target terapi. Faktor yang dapat mempengaruhi kontrol glikemik yang baik adalah pasien datang ke program atau forum yang mempelajari diabetes, memiliki asuransi kesehatan, melakukan monitoring gula darah sendiri di rumah dan adanya intervensi atau pemberian edukasi kepada pasien dapat meningkatkan pengetahuan tentang diabetes, kualitas hidup, perawatan diri, menurunkan gula darah puasa, $\mathrm{HbA} 1 \mathrm{c}$, kolesterol, tekanan darah ${ }^{1}$.
Hasil penelitian ini sama dengan penelitian sebelumnya yang menunjukan bahwa tidak ada korelasi antara tingkat pengetahuan dengan outcome klinik terutama glukosa darah namun terdapat korelasi antara tingkat pendidikan terhadap tingkat pengetahuan 3,9 . Faktor yang berkaitan dengan karakteristik pasien juga tidak menunjukan adanya hubungan dengan outcome klinik. Rendahnya kontrol glikemik pada pasien ditunjukan pada studi lain di Malaysia dan negara-negara berkembang ${ }^{10}$. Rendahnya kontrol glikemik diperkirakan karena pola makan penduduk di negara setempat yang tinggi karbohidrat, kurangnya aktifitas fisik dan pengetahuan tentang diabetes dan terapinya ${ }^{11}$, namun studi terkini menyebutkan bahwa kontrol glikemik tidak berhubungan dengan jenis kelamin, ras, indeks masa tubuh, adanya keturunan keluarga dari penderita diabetes, diet dan komorbid ${ }^{12}$. Pada penelitian penggunaan kombinasi dua obat yaitu metformin dan sulfonilurea memproleh angka ketercapaian target terapi paling baik sebesar $31 \%$ penggunaan kombinasi dua obat memperlihatkan hasil yang efektif karena mekanisme aksi kerja dua obat yang berbeda dan minimal resiko adverse effect ${ }^{12,13}$. Rendahnya kontrol glikemik juga ditemukan pada pasien dengan pemberian monoterapi ${ }^{14}$.

Pola terapi di puskesmas menggambarkan lebih banyak pasien yang menggunakan obat antidiabetik oral dibanding insulin dan lebih banyak menggunakan kombinasi dua obat terutama golongan metformin dan sulfonilurea, hal ini karena puskesmas merupakan tempat pelayanan kesehatan tingkat pertama dimana pasien sebagian besar menerima antidiabetik oral sebagai lini pertama dan merupakan 
tempat untuk kontrol rutin pasien yang sebelumnya telah mendapat antidiabetik. Berdasarkan jenis terapi, pasien menerima antidiabetik kombinasi metformin dan sulfonilurea terbanyak sejumlah 120 pasien namun yang mencapai target terapi sejumlah 62 pasien (31\%) dan yang tidak mencapai target terapi sejumlah 58 pasien (29\%).

Berdasarkan jumlah antidiabetik yang diterima baik kombinasi maupun monoterapi yang mencapai target terapi sebanyak 106 pasien (53\%) sisanya sebanyak 94 pasien (47\%) tidak mencapai target terapi. Hasil uji statistik menunjukan tidak ada hubungan antara jenis terapi $(p=0.596)$ dan jumlah terapi $(p=0,848)$ terhadap outcome klinik.

Diabetes merupakan penyakit kronis yang memerlukan terapi berkelanjutan, patient self care dan edukasi untuk mencegah terjadinya komplikasi. Peran farmasis adalah membantu pasien untuk lebih mengenal penyakit dan terapinya dengan cara memberikan edukasi yang tepat terkait penyakit diabetes, studi menunjukan bahwa intervensi farmasis dapat mempengaruhi outcome klinik dan kepuasan terapi pasien, yang merupakan indikator krusial kualitas pelayanan kesehatan dan merupakan kunci kepatuhan pasien dengan melakukan kegiatan misalnya support of self blood glucose monitoring (SMBG), monitoring kepatuhan pasien, dan mengidentifikasi masalah terkait terapi atau drug related problem (DRP) ${ }^{15,16}$.

\section{KESIMPULAN}

Skor rata-rata tingkat pengetahuan pasien adalah 12. Jumlah pasien dengan skor $<12$ adalah sebesar $106(57 \%)$ dan $\geq 12$ adalah sebesar $94(43 \%)$. Item pertanyaan yang paling banyak dijawab salah adalah pada item etiologi, patofisiologi dan self care. Hasil penelitian menunjukan bahwa tingkat pengetahuan tidak berhubungan dengan outcome klinik pasien. Penelitian ini dapat menjadi bahan masukan dan evaluasi mengenai konten materi edukasi diabetes kepada pasien. Meskipun tidak berhubungan secara langsung namun tetap perlu dilakukan pemberian edukasi penyakit diabetes melitus dan pengontrolan gula darah agar pasien dapat mencegah kemungkinan terjadinya komplikasi makrovaskular maupun mikrovaskular.

\section{DAFTAR PUSTAKA}

1. Fenwick EK., Xie J., Rees G., Finger RP., Lamoureux EL. Factors Associated with Knowledge of Diabetes in Patients with Type 2 Diabetes Using the Diabetes Knowledge Test Validated with Rasch Analysis. Khamseh ME, ed. PLoS ONE. 2013;8:e80593.

2. Ozcelik F., Yiginer O., Arslan E., et al., Association between glycemic control and the level of knowledge and disease awareness in type 2 diabetic patients. Pol Arch Med Wewn.2010;120(10): 399406.

3. Carrillo Alarcon LC. Level of Knowledge in Patients with Type 2 Diabetes Mellitus and its Relationship with Glycemic Levels and Stages of Grief According to Kübler-Ross. J Diabetes Metab. 2015;06(02).

4. Garcia AA., Villagomez ET., Brown SA., Kouzekanani K, Hanis CL. The Starr County Diabetes Education Study: Development of the Spanish-language diabetes knowledge questionnaire. Diabetes Care. 2001;24(1):16-21.

5. Al-Qazaz HK., Sulaiman SA., Hassali MA, Shafie AA, Sundram S. Diabetes knowledge and control of glycaemia among type 2 diabetes patients in Penang, Malaysia: Knowledge and glycaemia control in type 2 diabetes. $J$ Pharm Health Serv Res. 2012;3(1):49-55.

6. Al-Rasheedi AAS. The Role of Educational Level in Glycemic Control among Patients with Type II Diabetes Mellitus. Int J Health Sci. 2014;8(2):177-

7. Talmadge K., Philipson L., Reusch J., et al., Standar of Medical Care in Diabetes. Diabetes Care. 2018;41(1):S7-S11.

8. Shams N., Amjad S., Seetlani NK., Ahmed W. Diabetes Knowledge in Elderly Type 2 Diabetes Mellitus Patients and Association with Glycemic 
Control. J Liquat Uni Med Health Sci. 2016;15(02):71-7.

9. Dussa K. Assesment Of Diabetes Knowledge Using Diabetes Knowledge Questionnaire Among People With Type 2 Diabetes Mellitus. Asian J Pharm Clin Res. 2015;8(2):3.

10. Khattab M., Khader YS., Al-Khawaldeh A., Ajlouni K. Factors associated with poor glycemic control among patients with Type 2 diabetes. I Diabetes Complicat. 2010;24(2):84-89.

11. Almutairi MA., Said S., Zainuddin H. Predictors of Poor Glycemic Control Among Type Two Diabetic Patients. Am $J$ Med Sci. 2013, 3(2) :17-21. doi: 10.5923/j.ajmms.20130302.01.

12. Ahmad NS., Islahudin F., Paraidathathu T. Factors associated with good glycemic control among patients with type 2 diabetes mellitus. J Diabetes Invest. 2014;5(5):563-569.
13. Al Mansari A., Obeid Y., Islam N., et al., GOAL study: clinical and non-clinical predictive factors for achieving glycemic control in people with type 2 diabetes in real clinical practice. $B M J$ Open Diabetes Res \& Care. 2018;6(1):e000519.

14. Kibirige D., Akabwai GP., Kampiire L., Kiggundu DS.., Lumu W. Frequency and predictors of suboptimal glycemic control in an African diabetic population. Int J Gen Med.2017; Volume 10:33-38.

15. Hughes J., Wibowo Y., Sunderland B., Hoti K. The role of the pharmacist in the management of type 2 diabetes: current insights and future directions. Integr Pharm Res Pract. 2017;Volume 6:15-27.

16. Yigazu DM., Desse TA. Glycemic control and associated factors among type 2 diabetic patients at Shanan Gibe Hospital, Southwest Ethiopia. BMC Res Notes. 2017;10(1). 